\title{
NUMERICAL ANALYSIS OF THE WIDTH CONTROL OF THE EARLY-AGE CRACKS IN CONCRETE
}

\author{
R. Sonnenschein ${ }^{*}$, K. Gajdosova ${ }^{* *}$
}

\begin{abstract}
The design of the concrete structures focuses mainly on the effects of the direct load in terms of the construction safety. In connection with the use of the massive concrete structures and new technologies, the need to consider the effects of the indirect load increases. From the point of the view of significance of the seperating cracks for the serviceability and durability of concrete structures, the paper deals with the reinforcement ratio of longitudinal reinforcement to the maximum crack width limitation. This study is the background for the experimental investigation focused on the comparison of crack width control with steel and composite reinforcement.
\end{abstract}

Keywords: early-age cracks, width control of the cracks, numerical modeling

\section{Introduction}

Early-age cracks are formed by indirect loads, while the concrete does not yet reach its ultimate strength. Cracks are formed, when the tensile strength of concrete is exceeded. The risk is represented by separating cracks that cross the entire cross-section of the structure and cause water to penetrate the structure. The width of the cracks can be controlled by reinforcement and by this way limited to the desired value. In cracks with controlled width the self-healing can be consider. Crack width control is important in the structures such as tanks, reservoirs, basements structures without the use of the additional insulation (White Tanks), etc. The numerical model for the parametric study was calibrated based on the experimental program. Numerical models were created in the ATENA 3D software based on FEM. Within this parametric study, the effect of the reinforcement ration on the crack width was monitored.

\section{Assumptions for the analysis}

For the numerical analysis a nonlinear analysis was chosen, which can be used for both limit states (serviceability and ultimate), provided conditions of stability and continuity are met. Non-linear action of the materials is assumed (material properties represent real stiffness). For the concrete, a fracture-based model combining models for tensile (fracture) behavior - Rankin and pressure (plastic) behavior Drucker-Prager was used.

Numerical analysis consists of 16 models with reinforcement diameters of 12, 14, 16 and $20 \mathrm{~mm}$ and number of bars of 10,14, 16 and 18 at each surface. The loading of the models was done in 60 load steps with $0.2 \mathrm{~mm}$ deformation for each type of the reinforcement. The Gauss elimination method was chosen for the solution.

\footnotetext{
Ing. Robert Sonnenschein, PhD.: Department of Concrete Structures and Bridges, Fauclty of Civil Engineering, Slovak University of Technology, Radlinskeho 11; 810 05, Bratislava; SK, robert.sonnenschein@stuba.sk

** Assoc. Prof. Ing. Katarina Gajdosova, PhD.: Department of Concrete Structures and Bridges, Fauclty of Civil Engineering, Slovak University of Technology, Radlinskeho 11; 810 05, Bratislava; SK, katarina.gajdosova@stuba.sk
} 


\section{Parameters of the numerical model}

The concrete part of the elements was modeled with "3D Nonlinear Cementious 2" material. The material was defined by the characteristic compressive cube strength of concrete, the other parameters were automatically calculated by the program and adjusted according to the results of the laboratory tests of the materials. The reinforcement was characterized using a bilinear stress-strain diagram of reinforcing steel, which was obtained from a steel tensile test. In addition to the materials that the reinforced concrete element is made of, one more material has been used to assure the transfer of load to the element in the form of steel plates. For the steel plate, the "3D elastic isotropic" material is defined.

The geometry of the numerical model is shown in Fig. 1. The numerical model consists of three macro elements: a concrete element, two steel plates and bars of the longitudinal and transverse reinforcement.

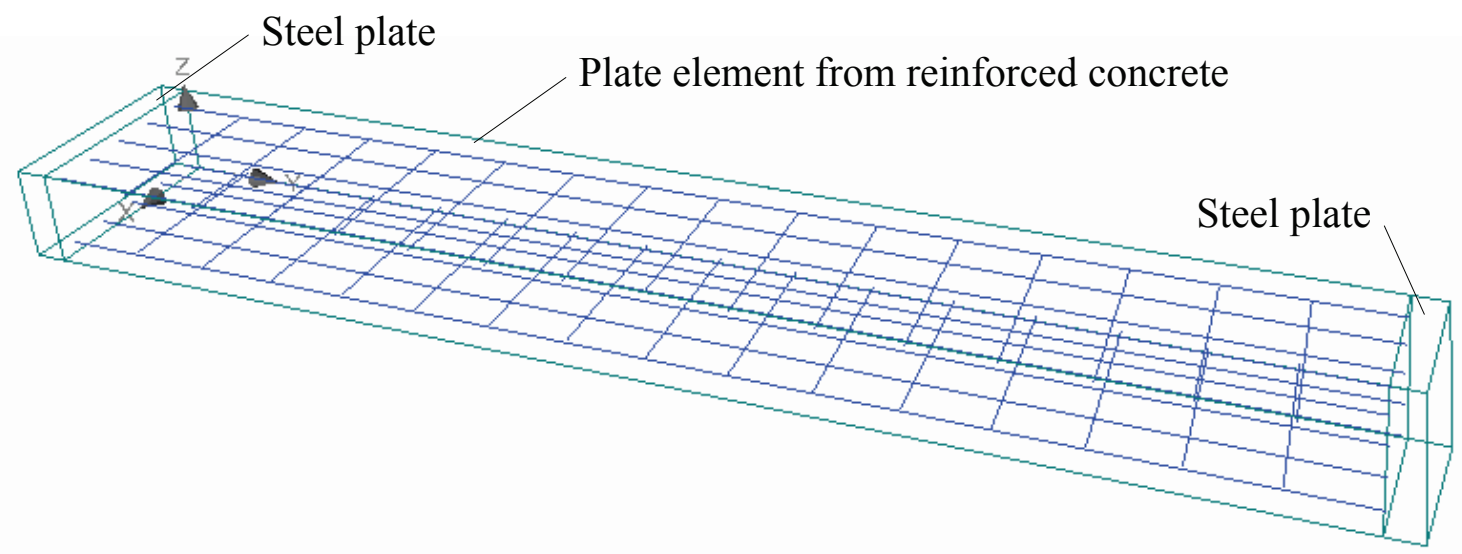

Fig. 1: Geometry of the analysis model

The load in the numerical model is given by two load states:

- Supports (Fig. 2a) - located on the surface of the specimen defined as follows:

$\circ$ fixing the movement in the direction of lengthening and vertical displacement at one end of the element,

- avoid moving in the transverse direction on the same side of the element.

- Deformation (Fig. 2b) - centered on the other end of the element, implemented in individual load steps, which represent a multiplicity of the input value of $0.2 \mathrm{~mm}$.

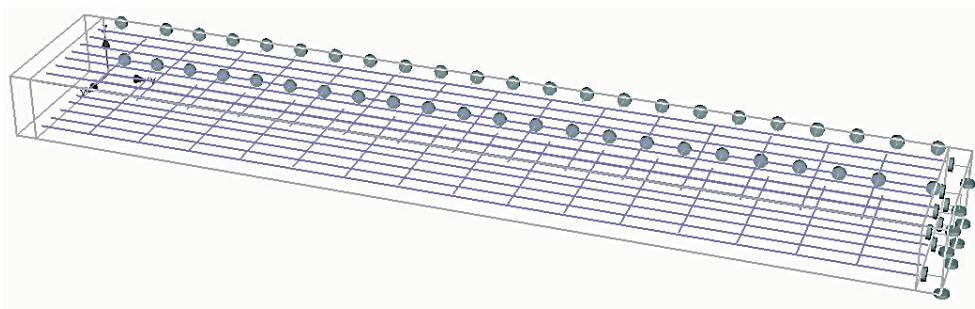

a)

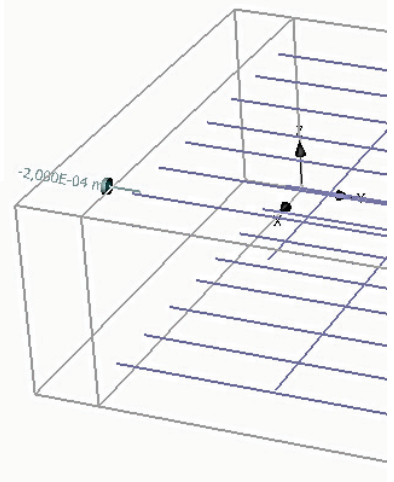

b)

Fig. 2: Load states - a) Supports and b) Deformation

Non-linear equations are addressed by the Arc-Length method, where the incremental load in the individual steps is not constant. Five monitoring points were selected to monitor the force, stress and cracks in the model (Fig. 3) - measurement of the drop of the support, stress in the longitudinal reinforcement at the upper and the lower surface, stress on the surface of the concrete and the global point for measuring the average crack width on the element. 


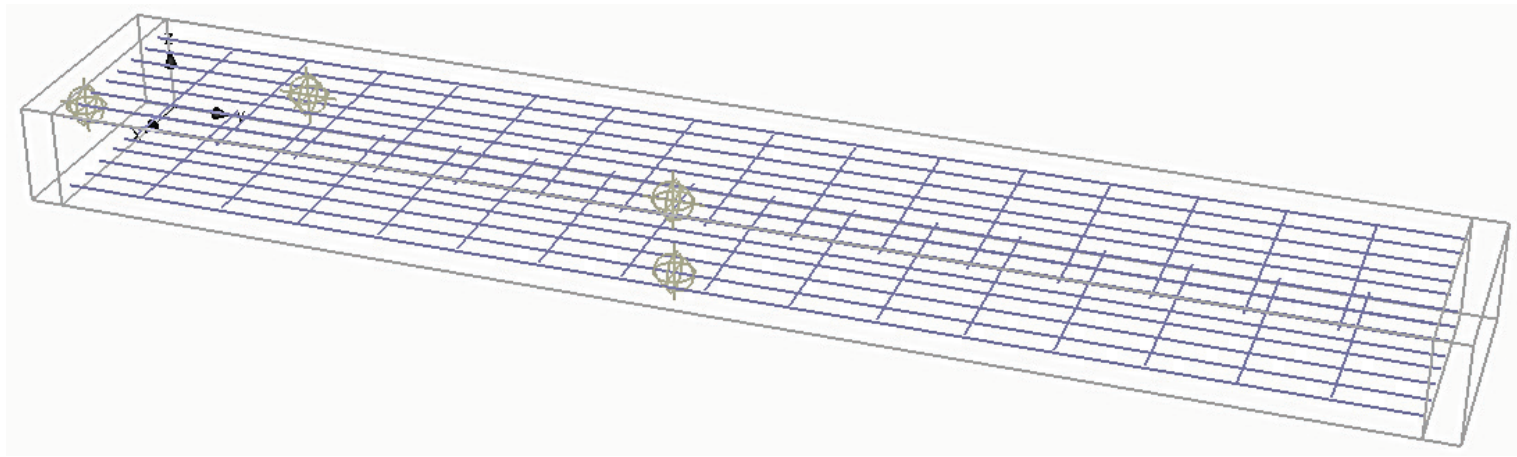

Fig. 3: Location of the monitoring points

\section{Results of the numerical analysis}

Numerical analysis allowed simulation of the behavior of the element during deformation - the stresses in the reinforcement and the average width of the cracks, depending on the increasing deformation, as well as the force induced by the deformation, were observed. Tab. 1 presents the values achieved for each stage of the exposure. The crack widths were determined in the stabilization cracked state of Fig. 4 and the stress in the reinforcement at the level of the yield strength.

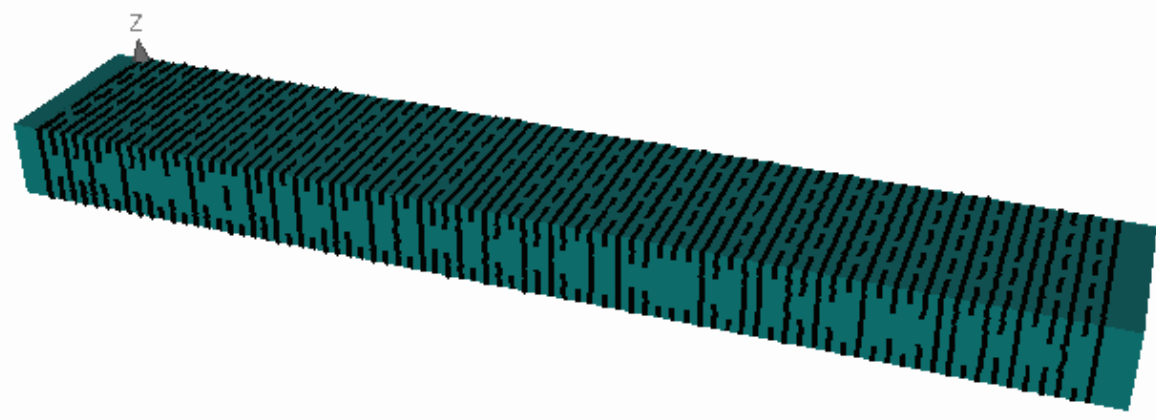

Fig. 4: State of the stabilized crack formation

Tab. 1: Average crack widths depending on the reinforcement ratio, strength in the reinforcement $510 \mathrm{MPa}$

\begin{tabular}{|c|c|c|c|c|c|c|c|c|c|c|c|c|}
\hline $\begin{array}{l}\text { Number of } \\
\text { bars [pcs.] }\end{array}$ & \multicolumn{3}{|c|}{$\varnothing 12$} & \multicolumn{3}{|c|}{$\varnothing 14$} & \multicolumn{3}{|c|}{$\varnothing 16$} & \multicolumn{3}{|c|}{$\varnothing 20$} \\
\hline \multirow{2}{*}{10} & 0.319 & \multirow{2}{*}{\multicolumn{2}{|c|}{-}} & 0.290 & \multirow[t]{2}{*}{$\rightarrow$} & \multirow[t]{2}{*}{$-9 \%$} & 0.268 & \multirow[t]{2}{*}{$\rightarrow$} & \multirow[t]{2}{*}{$-16 \%$} & 0.239 & \multirow{2}{*}{\multicolumn{2}{|c|}{$-25 \%$}} \\
\hline & -- & & & -- & & & -- & & & $--\downarrow$ & & \\
\hline \multirow{2}{*}{14} & 0.248 & \multirow{2}{*}{\multicolumn{2}{|c|}{$\begin{array}{l}\rightarrow \\
\downarrow\end{array}$}} & 0.229 & \multirow{2}{*}{$\begin{array}{l}\rightarrow \\
\downarrow\end{array}$} & \multirow{2}{*}{$-8 \%$} & 0.214 & \multirow{2}{*}{\multicolumn{2}{|c|}{$\begin{array}{l}\rightarrow \\
\downarrow\end{array}$}} & 0.193 & \multirow[t]{2}{*}{$\rightarrow$} & \multirow[t]{2}{*}{$-23 \%$} \\
\hline & $-22 \%$ & & & $-21 \%$ & & & $-20 \%$ & & & $-19 \%$ & & \\
\hline \multirow{2}{*}{16} & 0.229 & \multirow{2}{*}{\multicolumn{2}{|c|}{$\begin{array}{l}\rightarrow \\
\downarrow\end{array}$}} & 0.210 & \multirow{2}{*}{$\begin{array}{l}\rightarrow \\
\downarrow\end{array}$} & \multirow{2}{*}{$-8 \%$} & 0.197 & $\rightarrow$ & $-14 \%$ & 0.178 & \multirow{2}{*}{$\begin{array}{l}\downarrow \\
\downarrow\end{array}$} & \multirow[t]{2}{*}{$-22 \%$} \\
\hline & $-28 \%$ & & & $-28 \%$ & & & $-27 \%$ & $\downarrow$ & & $-26 \%$ & & \\
\hline \multirow{2}{*}{18} & 0.212 & \multirow{2}{*}{\multicolumn{2}{|c|}{$\begin{array}{l}\rightarrow \\
\downarrow\end{array}$}} & 0.196 & \multirow{2}{*}{$\begin{array}{l}\rightarrow \\
\downarrow\end{array}$} & \multirow{2}{*}{$-7 \%$} & 0.184 & \multirow{2}{*}{$\begin{array}{l}\rightarrow \\
\downarrow\end{array}$} & \multirow{2}{*}{$-13 \%$} & 0.167 & \multirow{2}{*}{\multicolumn{2}{|c|}{$-21 \%$}} \\
\hline & $-34 \%$ & & & $-33 \%$ & & & $-31 \%$ & & & $-30 \%$ & & \\
\hline
\end{tabular}




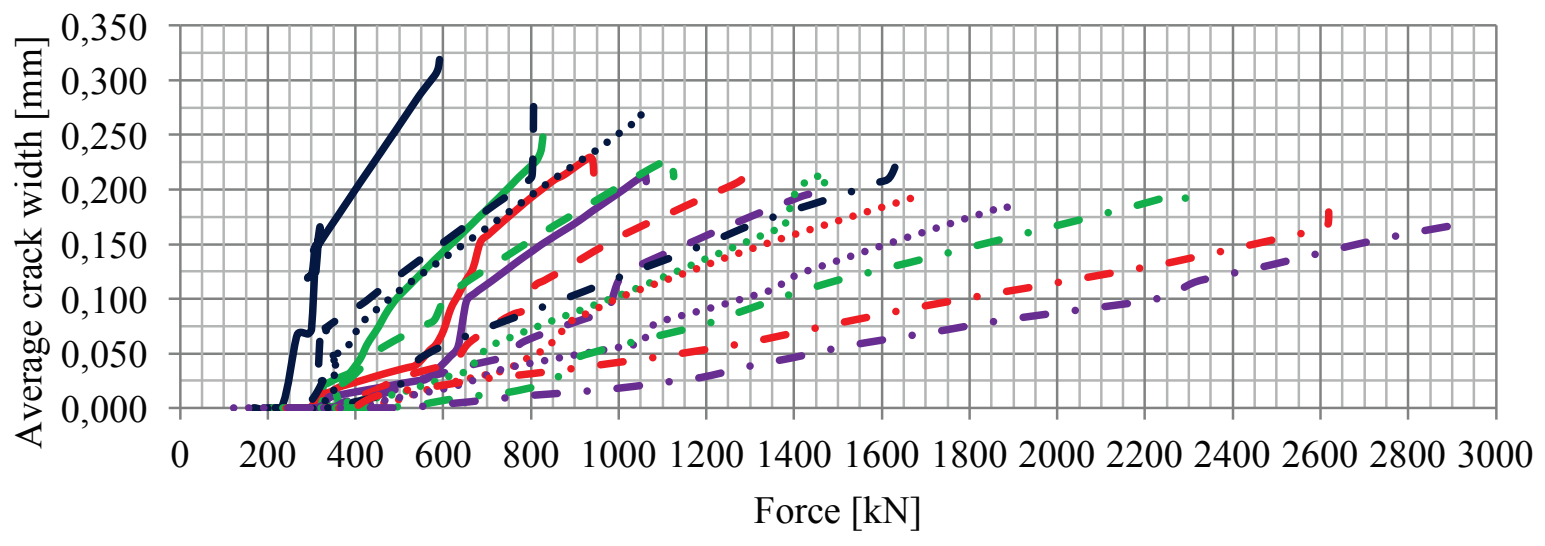

$$
\begin{aligned}
& \longrightarrow \rho=0.54 \varnothing=12 \longrightarrow \rho=0.75 \varnothing=12 \longrightarrow \rho=0.86 \varnothing=12 \longrightarrow \rho=0.97 \varnothing=12
\end{aligned}
$$

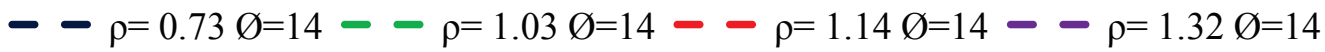

$$
\begin{aligned}
& \cdots \cdots \rho=0.96 \varnothing=16 \cdots \cdots \rho=1.34 \varnothing=16 \cdots \cdots \rho=1.53 \emptyset=16 \cdots \cdots \rho=1.72 \varnothing=16 \\
& \cdots \rho=1.50 \varnothing=20-\cdots \rho=2.09 \varnothing=20 \cdots \rho=2.39 \emptyset=20-\cdots \rho=2.69 \varnothing=20
\end{aligned}
$$

Fig. 5: Average crack widths for the different reinforcement ratio and diameter of reinforcement depending on the force

Tab. 2: Comparison of the width of the cracks depending on the amount of reinforcement bars

\begin{tabular}{ccc}
$\begin{array}{c}\text { Reinforcement } \\
\text { bars }\end{array}$ & $\rho[\%]$ & $\mathrm{W}_{\mathrm{m}}[\mathrm{mm}]$ \\
\hline $14 \varnothing 12$ & 0.753 & 0.248 \\
$10 \varnothing 14$ & 0.733 & 0.290 \\
\hline $18 \varnothing 12$ & 0.969 & 0.212 \\
$10 \varnothing 16$ & 0.957 & 0.268 \\
\hline $18 \varnothing 14$ & 1.319 & 0.196 \\
$14 \varnothing 16$ & 1.340 & 0.214 \\
\hline $16 \varnothing 16$ & 1.531 & 0.197 \\
$10 \varnothing 20$ & 1.496 & 0.239
\end{tabular}

\section{Conclusion}

The results of the parametrical study can be found confirming the expected trends:

- increasing in the reinforcement ratio $\rho=0.75$ to $2.1 \%$ caused a reduction in the average crack width of 8 to $22 \%$,

- at the same reinforcement ratio, the plate elements with a larger number of smaller diameter of bars have smaller cracks than elements with a smaller number of bar of larger diameter (Tab. 2).

\section{Acknowledgement}

This work was supported by the Slovak Research and Development Agency under the contract No. APVV-15-0658. 